\title{
Implementation and evaluation of a preprinted perioperative antimicrobial prophylaxis order form in a teaching hospital
}

\author{
Paul Au BSc (Pharm) ${ }^{1}$, Suzette Salama B Pharm PhD ${ }^{1}$, Coleman Rotstein MD FRCPC ${ }^{2}$
}

\begin{abstract}
P Au, S Salama, C Rotstein. Implementation and evaluation of a preprinted perioperative antimicrobial prophylaxis order form in a teaching hospital. Can J Infect Dis 1998;9(3):157-166.

OBJECTIVE: To determine the effect of a preprinted perioperative antimicrobial prophylaxis order form on the appropriateness, standardization and cost of surgical prophylaxis.

DESIGN: A pre- and postintervention prospective study with evaluation of drug acquisition costs in selected surgical procedures.

SETTING: A 420-bed teaching hospital in the Hamilton-Wentworth region.

PATIENTS: A three-month survey of 901 consecutive patients followed by a two-month trial period of 725 consecutive patients undergoing general surgery, orthopedic and urological procedures.

INTERVENTION: A perioperative antimicrobial prophylaxis order form was developed based on guidelines from the literature and input from physician and nursing staff. The form was introduced through educational inservices and put into operation.

MEASUREMENT: The measurement of antimicrobial perioperative prophylaxis appropriateness and drug acquisition costs were assessed pre- and postintroduction of the order form. Subsequently, prescriber compliance and satisfaction with the program were also evaluated.

RESULTS: Appropriateness of perioperative antimicrobial surgical prophylaxis was increased from $36 \%$ in the baseline period to $79 \%$ in the trial period $(\mathrm{P}<0.0001)$. A reduction of $\$ 440.71(\$ 23.20 /$ procedure) in drug acquisition costs was observed for 19 matched hip and knee prosthetic surgical procedures between the baseline and trial periods. In addition, compliance with the perioperative order form rose steadily during the trial period. Physician prescribers reported that the form was used, and was appropriate and user-friendly but that it did not influence their prescribing habits. Nurses responded that the form was helpful and improved the timing of prophylaxis.

CONCLUSIONS: The perioperative antimicrobial prophylaxis order form standardized antimicrobial administration time and resulted in an increase in appropriateness. A reduction in antimicrobial costs for surgical procedures was realized. This quality improvement project has enhanced the quality of patient care.
\end{abstract}

Key Words: Antimicrobial therapy, Order form, Perioperative, Prophylaxis

voir page suivante

\footnotetext{
${ }^{1}$ Department of Pharmacy; ${ }^{2}$ Division of Infectious Diseases and Department of Medicine, Henderson General Site, Hamilton Health Sciences Corporation and McMaster University, Hamilton, Ontario

Correspondence and reprints: Dr Coleman Rotstein, McMaster Medical Unit, Henderson General Hospital, 711 Concession Street, Hamilton, Ontario L8V 1C3. Telephone 905-574-3301, fax 905-575-7320, e-mail crotstei@fhs.McMaster.CA

Received for publication March 6, 1997. Accepted July 25, 1997
} 


\section{Mise en place et évaluation d'un formulaire de prescription pré-imprimé pour administrer une prophylaxie antimicrobienne péri-opératoire dans un hôpital universitaire}

OBJECTIF : Déterminer l'impact d'un formulaire de prescription pré-imprimé pour administrer une prophylaxie antimicrobienne péri-opératoire sur la pertinence, la standardisation et le coût d'une prophylaxie chirurgicale.

MODÈLE : Une étude prospective pré et post-intervention associée à une évaluation du coût d'acquisition des médicaments lors d'interventions chirurgicales choisies.

CONTEXTE : Un hôpital universitaire de 420 lits dans la région de Hamilton-Wentworth.

PATIENTS : Une enquête de trois mois d'une série de 901 patients suivie d'une période d'essai de deux mois sur 725 patients consécutifs subissant une chirurgie générale, orthopédique ou urologique.

INTERVENTION : Un formulaire de prescription pré-imprimé pour administrer une prophylaxie antimicrobienne périopératoire a été conçu sur la base de lignes directrices tirées de la littérature et des commentaires apportés par les médecins et le personnel infirmier. Le formulaire a été introduit par le biais de séances de formation dans les services puis, mis en opération.

MESURES : Les mesures de la pertinence d'une prophylaxie antimicrobienne péri-opératoire et des coûts d'acquisition des médicaments ont été évaluées avant et après l'introduction du formulaire. Ensuite, on a évalué la fidélité des prescripteurs et le degré de satisfaction envers le programme.

RÉSULTATS : La pertinence d'une prophylaxie chirurgicale antimicrobienne péri-opératoire est passée de $36 \%$ dans la période de référence à $79 \%$ dans la période d'essai (P0,0001). Une réduction de 440,71 dollars (23,20 dollars par intervention) dans le coût d'acquisition des médicaments a été observée pour 19 interventions chirurgicales sur des prothèses de genoux et de hanche appariées entre la période de référence et les périodes d'essai. De plus, la fidélité envers le formulaire péri-opératoire s'est accrue graduellement pendant la période d'essai. Les médecins-prescripteurs ont signalé qu'ils utilisaient le formulaire, que ce dernier était approprié et d'emploi facile mais qu'il n'influençait pas leurs habitudes de prescription. Pour les infirmières, le formulaire était utile et permettait de mieux planifier le moment d'administration de la prophylaxie.

CONCLUSIONS : Le formulaire de prophylaxie antimicrobienne péri-opératoire a standardisé le moment d'administration et résulté en une utilisation plus appropriée de la prophylaxie antimicrobienne. Une réduction du coût des médicaments antimicrobiens administrés lors des interventions chirurgicales a été réalisée. Ce projet d'amélioration de la qualité a rehaussé la qualité des soins dispensés aux patients.

$\mathrm{P}$ rescription drugs contribute significantly to hospital expenditures and account for approximately $5 \%$ to $20 \%$ of a hospital's global budget (1). Antimicrobial agents constitute a substantial proportion of a hospital's drug inventory (about $25 \%)(2)$ and drug acquisition budget $(20 \%$ to $50 \%)(3,4)$. However, because of the perception that antimicrobial agents are associated with low risk of toxicity, these therapeutic drugs have resulted in varying degrees of inappropriate use (5-13). Therefore, it is not surprising that these drugs have received increasing scrutiny during an era of cost containment $(14,15)$.

Surgical site infections account for up to $24 \%$ of nosocomial infections (16). Consequences of these infections include compromised quality of life for patients and significant treatment expenditures. Antimicrobial prophylaxis has proven benefits in surgical procedures associated with high infection rates, ie, clean-contaminated or contaminated operations (17-19). Recently, the benefit of antimicrobial prophylaxis in clean surgical procedures has also been demonstrated $(20,21)$ but some controversies still persist $(22,23)$.

Because perioperative prophylactic antimicrobials can comprise up to $30 \%$ of all administered antimicrobial agents (24), they form a significant portion of total antimicrobial usage and cost. The agents used in perioperative prophylaxis are also subject to inappropriate use (25). Efforts to encourage the appropriate use of these drugs for perioperative prophylaxis have resulted in the formulation of several guidelines (26-35). Although prescribers may initially adhere to written prophylaxis guidelines for a time after their introduction, this behaviour decays with the passing of time, if it is not continuously reinforced. This reinforcement may be very labour-intensive.
However, it may be easier to alter inappropriate antimicrobial usage in perioperative prophylaxis that is a nonlifethreatening situation, in contrast to a therapeutic scenario that may be life-threatening. Physicians are less apt to alter their prescribing practices in a therapeutic situation where antimicrobial usage is perceived as necessary than in surgical prophylaxis where the use of antimicrobials is merely to prevent possible postsurgical infections. As a result, efforts to influence physicians' prescribing patterns of perioperative prophylaxis may be more productive.

Strategies to limit the inappropriate drug use in the hospital setting include the following methods: educational activities for physicians $(36,37)$ such as Pharmacy and Therapeutics Committee newsletters or inservices (38); peer review (39); academic detailing (40); an antibiotic handbook $(2,41,42)$; a controlled formulary system $(15,43)$; automatic stop order policies (43); drug detailing by pharmaceutical representatives (44); infectious disease specialist consultations (43); therapeutic interchange policies $(14,15)$; and a preprinted antimicrobial order form $(2,43,45-48)$. These methods have met with varying degrees of success $(2-4,14,15)$, but in general, the most successful and lasting effects have been recorded through prescribing restrictions when an order form or computer-assisted decision support is employed. In addition, an order form may serve as an educational tool for residents and may be an effective quality assurance item to monitor the use of antimicrobial agents.

In the authors' institution, a preliminary drug utilization review over a three-month period demonstrated that approximately $64 \%$ of perioperative antimicrobial use was inappropriate, based on the surgical indication, antibiotic selection, du- 
ration, frequency or dose ordered. Moreover, it was noted that there was no standardized time of administration of perioperative antimicrobials, resulting in potential delays of up to $4 \mathrm{~h}$ from the time of injection to the time of the incision.

As a result of the perceived inappropriate use of perioperative antimicrobial prophylaxis, we developed a series of procedure-specific recommendations that were recorded on order forms for a number of surgical procedures. The order forms were implemented and evaluated over two months. Our objectives were to standardize the use of perioperative prophylactic antimicrobial regimens, promote the appropriate use of surgical prophylaxis, introduce an educational tool that would have a lon-glasting effect on surgeons' prescribing patterns, and reduce costs. A comparison of the baseline data with those of the period following the introduction of the perioperative antimicrobial prophylaxis order form is described.

\section{MATERIALS AND METHODS}

Subjects: The study design was a pre- and postintervention comparison of the use of antimicrobial agents employed in surgical prophylaxis in a 420-bed teaching facility in the HamiltonWentworth region. The baseline data were collected on consecutive patients undergoing surgical procedures over three months. Due to the regionalization of health services, data on perioperative prophylaxis in cases of general, orthopedic and urological surgery only were collected. Information on prophylactic regimens for the prevention of bacterial endocarditis for these cases was also included. Demographic data on all baseline patients were accrued. Subsequently, information was gathered once more on consecutive patients over two months after the introduction of the perioperative antimicrobial prophylaxis order form for the same surgical specialties.

Order form description: A MEDLINE literature search from 1985 to 1995 was performed to retrieve relevant review articles and randomized clinical trials on perioperative antimicrobial prophylaxis. A literature review of these clinical trials and practice guidelines formed the basis for the development of the preliminary draft of the perioperative antimicrobial prophylaxis order form. The recommendations were formulated so that they were procedure-specific and grouped for general surgery, orthopedics and urology, respectively. All staff concerned (surgeons, infectious disease specialists, nursing staff, pharmacists and pharmacy technicians) were consulted to obtain feedback about the recommendations and form content. Approval of the form was achieved through consensus obtained from all user representatives. The preprinted order forms (Appendix A) were designed to include all the possible surgical procedures performed by the surgical services at this institution for which antimicrobial prophylaxis was indicated. As an educational reminder, literature-approved prophylaxis indications for some procedures were also included on the form. Alternative prophylactic regimens were provided when beta-lactam allergy or methicillin-resistant staphylococci were problems. The order form was set up so that the prescribing physician need only check off the desired prophylactic regimen for the surgical procedure to be performed and sign at the bottom of the form. A 'no prophylaxis' option was available.
Introduction of the order form: After approval of the form by the Pharmacy and Therapeutics Committee of the hospital, extensive educational inservices to all participating nurses, house staff and attending physicians were initiated. For elective surgical procedures, antimicrobial prophylaxis order forms were completed in preoperative clinics or physicians' private offices. Pharmacy technicians prepared the daily requirement of perioperative antimicrobials in minibags and delivered them each morning to the reception area adjacent to the operating room. All preoperative antimicrobial doses except for vancomycin that required infusion times of $1 \mathrm{~h}$ were administered in this reception area just before entering the operating room. Vancomycin infusions were commenced on the respective nursing units because of lack of space in the operating room reception area for prolonged infusions. The administration of the antimicrobial agents for nonelective procedures was based on the completed order form that accompanied each patient to the operating room. Blank order forms were available at every nursing unit.

Analysis: An assessment of the appropriateness of perioperative antimicrobial usage and drug acquisition costs was measured pre- and postintroduction of the perioperative antimicrobial order form. Appropriateness was evaluated by using the established recommendations on the order form according to five predetermined criteria: indication; choice of agent; dosage; frequency of administration; and duration of prophylaxis. When more than one reason for inappropriateness was found for a particular perioperative antimicrobial prophylaxis prescription, the primary cause of inappropriateness was deemed to be the most important inappropriate criterion documented. The $\chi^{2}$ test was used to compare categorical variables while Student's $t$ test was used for continuous variables. Statistical significance was set at $\mathrm{P} \leq 0.05$. A cost minimization analysis was performed on a selected group of surgical procedures (hip and knee prostheses only) during both periods to demonstrate the impact of the new program. Nineteen hip and knee prosthetic surgical procedures were matched on the basis of the same procedure and the same surgeon performing the procedure during the baseline and trial periods. Drug acquisition costs in the baseline period were compared with those following the intervention. Current costs of antimicrobial agents were used to calculate the cost for both study periods.

The order form was also evaluated for its acceptability by users by measuring the compliance rate of form completion. In addition, satisfaction surveys were circulated among prescribers and participating operating room nurses. The physicians' satisfaction survey questionnaire assessed 10 domains regarding background knowledge of perioperative prophylaxis, knowledge of the existence of the form and the form's use, appropriateness, educational benefit, time efficiency and design. Each response was scored on a five-point scale ranging from strongly disagree to strongly agree. General comments were also invited. Similarly, the participating operating room nurses responded to a satisfaction survey comprised of five domains including an assessment of workload, efficiency in carrying out perioperative antimicrobial prophylaxis orders 
TABLE 1

Patient demographics for patients eligible for perioperative antimicrobial prophylaxis during baseline and trial periods

\begin{tabular}{lccc}
\hline $\begin{array}{l}\text { Patient } \\
\text { characteristic }\end{array}$ & $\begin{array}{c}\text { Baseline } \\
\text { period } \\
(\mathbf{n = 9 0 1 )}\end{array}$ & $\begin{array}{c}\text { Trial period } \\
(\mathbf{n = 7 2 5 )}\end{array}$ & $\mathbf{P}$ \\
\hline Mean age & $54 \pm 18$ & $56 \pm 18$ & 0.06 \\
Sex (male to female) & $58 \%: 42 \%$ & $53 \%: 47 \%$ & 0.04 \\
Surgical procedures $\mathrm{n}(\%)$ & & & \\
General surgery & $387(43 \%)$ & $303(42 \%)$ & 0.6 \\
Orthopedics & $240(27 \%)$ & $267(37 \%)$ & 0.00001 \\
Urology & $274(30 \%)$ & $155(21 \%)$ & 0.0003 \\
\hline
\end{tabular}

and clarity of the form. This was also scored on a five-point scale. Subsequently, the mean response scores for each question were calculated for both questionnaires.

\section{RESULTS}

Nine hundred and one patients were followed in the threemonth baseline period while 725 were enrolled in the two-month trial period (Table 1). While there were no significant differences in the ages of the patients in the two groups, there was a difference in the sex ratio and distribution of the types of surgical procedures. In both periods, general surgery procedures were performed most frequently. However, there were significantly more urological procedures performed in the baseline than during the trial period. In addition, although urological procedures outnumbered orthopedic procedures in

TABLE 2

Appropriateness of perioperative antimicrobial prophylaxis during baseline and trial periods

\begin{tabular}{|c|c|c|c|}
\hline \multirow[b]{2}{*}{ Surgical categories } & \multicolumn{3}{|c|}{ Number appropriate/Number of cases (\%) } \\
\hline & Baseline & Trial & $\mathbf{P}$ \\
\hline General surgery & $106 / 387(27 \%)$ & $217 / 303(72 \%)$ & $<0.0001$ \\
\hline Biliary tract & $8 / 75(11 \%)$ & $55 / 62(89 \%)$ & \\
\hline Gastroduodenal & $0 / 3(0 \%)$ & $-*$ & \\
\hline Appendectomy without peritonitis or perforation & - & $3 / 3(100 \%)$ & \\
\hline Elective colon or small bowel & $3 / 29(10 \%)$ & $16 / 29(56 \%)$ & \\
\hline Herniorrhaphy & 10/99 (10\%) & $72 / 84(86 \%)$ & \\
\hline Division of adhesions & $2 / 11(18 \%)$ & $5 / 5(100 \%)$ & \\
\hline Mastectomy \pm lymph node dissection & $1 / 8(13 \%)$ & $9 / 14(67 \%)$ & \\
\hline Others & $82 / 162(51 \%)^{\dagger}$ & $57 / 106(54 \%)^{\ddagger}$ & \\
\hline Orthopedics & $104 / 240(43 \%)$ & $226 / 267(85 \%)$ & $<0.0001$ \\
\hline Joint arthroplasty & $36 / 82(44 \%)$ & $115 / 143(80 \%)$ & \\
\hline Open reduction and internal fixation of fracture & $0 / 2(10 \%)$ & $8 / 9(89 \%)$ & \\
\hline Osteotomy & $3 / 6(50 \%)$ & $4 / 5(80 \%)$ & \\
\hline Anterior cruciate ligament repair & $2 / 5(40 \%)$ & $3 / 3(100 \%)$ & \\
\hline Excision of tumour & - & $4 / 5(80 \%)$ & \\
\hline Lower limb amputation in diabetic patient & - & $1 / 2(50 \%)$ & \\
\hline Others & $63 / 144(44 \%)^{\S}$ & $91 / 100(91 \%)^{\top}$ & \\
\hline Urology & $110 / 274(40 \%)$ & $128 / 155(83 \%)$ & $<0.0001$ \\
\hline Endoscopic surgery & $68 / 84(37 \%)$ & $82 / 99(83 \%)$ & \\
\hline Prosthetic implants and open surgery not involving the bowel & $17 / 27(63 \%)$ & $9 / 13(69 \%)$ & \\
\hline Open surgery involving the bowel & - & $2 / 3(67 \%)$ & \\
\hline Others & $25 / 63(40 \%)^{* *}$ & $35 / 40(88 \%)^{\dagger+}$ & \\
\hline
\end{tabular}

${ }^{*}$ No surgeries of this type performed; ${ }^{+}$Other general surgery procedures during baseline period (segmental breast resection 39 , breast biopsy 22, hemorrhoidectomy 15, fistulectomy 12, sphincterotomy 12, axillary lymph node excision 12, lymph node biopsy 10, excision of gynecomastia 7, insertion of Porta-cath 7, laparotomy 7, liver biopsy 6, vein ligation and stripping 5, excision of lesion 3, splenectomy 3 and thyroidectomy 2); ${ }^{\ddagger}$ Other general surgery procedures during trial period (breast biopsy 19, segmental resection breast 17, hemorrhoidectomy 10, fistulectomy 9, excision of gynecomastia 8, lymph node excision 6, sphincterotomy 6, laparotomy 5, liver biopsy 5, insertion of Port-a-cath 5, splenectomy 5, excision of lesion 3, vein ligation and stripping 3, thyroidectomy 3 and lymph node biopsy 2); ${ }^{\$}$ Other orthopedic procedures during baseline period (arthroscopy 98, arthroscopic debridement 21, excision of extremity lesion 9, bunionectomy 7, excision of exostosis 5, excision of bursa 3 and ankle reconstruction 1); "Other orthopedic procedures during trial period (arthroscopy 77, arthroscopic debridement 5, bunionectomy 5, excision of bursa 4, excision of exostosis 3, excision of extremity lesion 3, ankle reconstruction 1 and shoulder repair 1); ** Other urological procedures during baseline period (vasectomy 18, circumcision 15, hydrocelectomy 9, epididymectomy 7 , pelvic node dissection 7, prostate biopsy 4 and cystoscopy 3 ); ${ }^{\text {t+ }}$ Other urology procedures during trial period (vasectomy 11, circumcision 10, cystoscopy 5 , endocarditis prophylaxis 3, epididymectomy 3, hydrocelectomy 3, pelvic node dissection 3, meatotomy 1 and prostate biopsy 1) 
the baseline period, this trend was reversed in the trial period when more orthopedic than urological procedures were completed.

Overall, the use of the perioperative antimicrobial prophylaxis order form increased appropriate usage of antimicrobial agents from $36 \%$ in the baseline period to $79 \%$ in the trial period $(\mathrm{P}<0.0001)$. The greatest improvement was noted among the general surgery procedures $(27 \%$ versus $72 \%$ ) (Table 2 ). Similarly, improvement in the appropriateness of antimicrobial prophylaxis was also observed with orthopedic ( $43 \%$ versus $85 \%, \mathrm{P}<0.0001)$ and urological procedures $(40 \%$ versus $83 \%$, $\mathrm{P}<0.0001$ ) between the baseline and trial periods. However, differences were present in the number of surgical procedures in each surgical category between the baseline and trial periods.

The reasons for inappropriate usage of antimicrobial prophylaxis were also documented. During the baseline period, inappropriate usage was based on only three of the aforementioned five criteria - improper indication, inappropriate agent and inappropriate dose. No data could be captured with respect to the frequency of administration and duration of prophylaxis due to incomplete computer data entry by the hospital's pharmacists. Based on the information for the general surgery procedures, perioperative prophylaxis was deemed inappropriate because of an improper indication 94\% (263 of $281)$ of the time and the wrong antimicrobial agent in $6 \%(17$ of 281). Similarly for orthopedic procedures, the prophylactic agents were judged to be inappropriate due to the wrong indication, wrong dose and wrong antimicrobial in 84\% (114 of 136), $10 \%$ (13 of 136) and $7 \%$ (9 of 136) of cases, respectively. Finally, for the urological procedures, $46 \%$ (76 of 164) of the prophylactic agents were inappropriate based on the wrong indication, $54 \%$ ( 88 of 164 ) based on the wrong drug and $0 \%$ due to the wrong dosage.

During the trial period, the criteria of appropriateness employed were the dose, drug, indication, frequency and the duration of prophylaxis. For general surgical procedures, inappropriate prophylaxis use was caused primarily by the wrong medication $(84 \%, 72$ of 86$)$ and to a lesser extent by the wrong drug ( $9 \%$, eight of 86 ), wrong dose ( $3 \%$, three of 86$)$, wrong duration $(3 \%$, three of 86$)$ and wrong frequency $(0 \%)$. Inappropriate prophylaxis for the orthopedic procedures resulted from the wrong indication $(41 \%, 17$ of 41$)$, wrong duration $(22 \%$, nine of 41$)$, wrong drug (22\%, 9 of 41$)$, incorrect dose $(15 \%, 6$ of 41 ) and wrong frequency (0\%). Finally, for urological procedures, inappropriate use of antimicrobial prophylaxis was due to the wrong indication $(59 \%, 16$ of 27$)$, wrong dose $(30 \%$, eight of 27$)$, wrong duration ( $7 \%, 2$ of 27$)$, wrong drug ( $7 \%$, two of 27 ) and wrong frequency ( $0 \%$ ). Thus, the most common reason for inappropriateness of perioperative prophylaxis was that prophylaxis was administered when it should not have been. Overall, during the baseline period $78 \%$ (453 of 581) of inappropriate antimicrobial prophylaxis resulted from prescribing prophylaxis incorrectly for a procedure that did not require it. Subsequently, during the trial period 68\% (105 of 154) of inappropriate usage was judged to be caused by prescribing for the wrong indication.

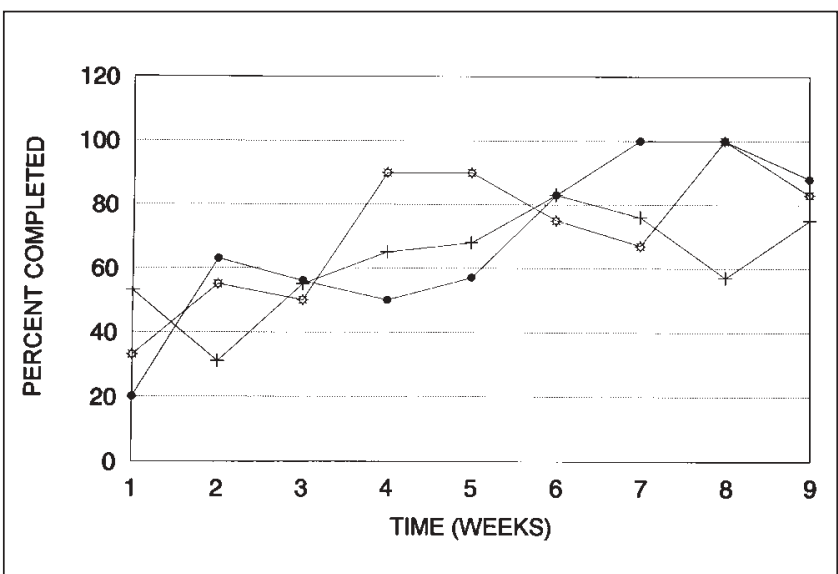

Figure 1) Physicians' compliance with the perioperative antimicrobial order form. General surgery; + Orthopedics surgery; O Urological surgery

For 19 matched hip and knee prosthetic orthopedic surgeries, drug acquisition costs showed a substantial cost differential between the two study periods. Drug acquisition costs were $\$ 754.81$ during the baseline period versus $\$ 314.10$ during the trial period, a reduction of $\$ 440.71$ (a decline of $58.4 \%$ ). This observed drug cost savings was equivalent to $\$ 23.20$ per procedure. If the cost reduction per procedure is extrapolated to all 416 hip and knee prosthetic surgeries performed at this institution annually, a total savings of approximately $\$ 9,651$ could be realized. This example was chosen because the type and number of surgical procedures as well as the surgeon were completely matched for the two time periods.

Prescriber compliance in completing the antimicrobial prophylaxis order form is shown in Figure 1. There was a trend of increasing compliance with time, reaching a maximum of $100 \%$ for general and urological surgeons by the eighth week of the trial. There were declines in the compliance rates for orthopedic surgeons in the seventh and eighth weeks. When the data were plotted for the four individual orthopedic surgeons, there was some variation among them.

Fourteen surgeons participated in this trial, and their opinions were canvassed by means of a satisfaction questionnaire at the end of the study period. The response rate for completing the questionnaire was $64 \%$. The mean score out of five for each question of the questionnaire was calculated. In general, surgeons commented that the regimens included in the form were used (mean score 4.0) and appropriate (mean score 3.3), while the form (mean score 3.5) and design (mean score 3.3) were user-friendly. However, the surgeons felt that the form did not influence their prophylaxis choice (mean score 2.4) and that it was not a good educational tool (mean score 2.5). Furthermore, they recommended that cost data be included on the order form. A different questionnaire was distributed to each of the participating nurses and 20 returned questionnaires. Each question was once again scored out of a maximum of five. They responded overwhelmingly that the order form was well designed (mean score 4.0), clinically helpful (mean score 3.8), improved the timing of prophylaxis (mean 
score 3.7) and should be continued (mean score 4.1). Nevertheless, the nurses voiced the concern that the form increased their workload (mean score 2.5).

\section{DISCUSSION}

As demonstrated by the increase in appropriate perioperative antimicrobial usage following the implementation of the prophylaxis order form, this strategy was a very effective means of controlling antimicrobial use and improving physicians' prescribing practice habits. However, the authors are aware that such restrictive measures are not universally applicable and their success may vary from institution to institution. We and others (4) believe that obtaining consensus agreement among the participants and feedback about the program were the key factors for its acceptance. In the process of developing our order form, several times surgeons and nurses were invited for discussion and feedback to arrive at a consensus for the final draft of the form. Accordingly, the form underwent numerous alterations to accommodate all reasonable suggestions. Problems with the form were anticipated, and we made every effort to deal expeditiously with these problems.

As a result of close monitoring and reminders to the prescribing physicians to use the form, a gradual increase in compliance to approximately $100 \%$ was achieved. We were assisted in achieving this compliance by the nurse stakeholders who welcomed the standardized format of the preprinted orders. The forms replaced the previously disorganized preoperative orders in the doctor's order section of the patient's medical record. A decrease in the compliance rate during the final two weeks of the trial period (Figure 1) could have been caused by an unanticipated shortage of order forms; only a limited number had been printed. We acknowledge that a natural decay of compliance can occur unless concurrent educational reinforcement is provided.

The success of our program underscores the fact that although standards and guidelines for surgical prophylaxis have been promulgated in recent years, they have had minimal effect on changing physicians' prescribing habits. According to our baseline data, $36 \%$ of prophylactic regimens were prescribed appropriately based on the predetermined criteria. Common causes of inappropriate use included an improper indication for prophylaxis (94\%), not choosing an agent with adequate coverage, using a more expensive broad spectrum drug where a less expensive agent would have sufficed, and injudicious use of vancomycin. The injudicious use of vancomycin is particularly vexing in light of the emergence of vancomycin-resistant enterococci (49) and guidelines published by the Hospital Infection Control Practices Advisory Committee on vancomycin use (50).

The implementation of the antimicrobial prophylaxis order form resulted in substantial drug acquisition cost savings of $\$ 23.20$ per procedure for orthopedic prosthetic hip and knee procedures. Thus, substantial drug cost savings could be realized with this policy. In addition, further savings can be projected because of the decrease in the number of doses dispensed (cost of approximately $\$ 8.20$ per intravenous dose administered) (51).
Another positive impact of the antimicrobial prophylaxis order form was the standardization of the timing of antimicrobial prophylaxis administration. Studies have demonstrated that antimicrobial prophylaxis infused within 30 to 60 mins before the surgical incision is optimal $(52,53)$, while prophylaxis administered too early, ie, longer than $2 \mathrm{~h}$ before the incision is ineffectual. In our study, we ensured that all preoperative antimicrobial prophylaxis except for vancomycin was administered in the operating room reception area just before entering the operating room (within about 45 mins of the surgical incision time). This replaced the previous practice of administering antimicrobial prophylaxis on the nursing unit where delays of up to $4 \mathrm{~h}$ occurred before the surgical incision. Unfortunately, comparison data on administration times between our study periods could not be completed because of poor documentation.

Our study results have a number of limitations. First, we were unable to arrive at total drug acquisition cost reductions due to the lack of comparability of surgical procedures during the baseline and study periods. Second, we did not achieve $100 \%$ appropriateness for antimicrobial prophylaxis because some surgeons failed to prescribe perioperative antimicrobial prophylaxis even when clinically indicated as suggested by the literature. Surgeons were not compelled to prescribe prophylaxis if they did not wish to do so. In addition, it was difficult to record all the reasons for inappropriate usage for each surgical procedure. We were only able to document three criteria for inappropriateness during the baseline period in contrast to all five criteria in the trial period. Thus, our estimate of the rate of inappropriate perioperative prophylaxis for the baseline period was conservative, compared with the more stringent criteria applied to the trial period. Finally, we could not explore changes in surgical wound infection rates subsequent to the introduction of our prophylaxis order form because of the heterogeneity of our surgical procedure categories. Nevertheless, our data highlight the development and acceptance of the order form with improvement in prescribing patterns.

In conclusion, perioperative antimicrobial prescribing practices were standardized, appropriateness improved and cost reduced in participating surgical services using our prophylaxis order form. With these encouraging results, our Pharmacy and Therapeutics Committee has approved this program as a hospital-wide policy and we are currently expanding it to other surgical services within our corporation. Besides the aforementioned benefits and the form's educational merit, it functioned as a multidisciplinary continuous quality improvement project to improve patient care.

\section{REFERENCES}

1. Ryan BA. The rising cost of pharmaceuticals: An industry observer's perspective. Am J Hosp Pharm 1993;50(Suppl 4):S3-4.

2. Girotti MJ, Fodoruk S, Irvine-Meek J, Rotstein OD. Antibiotic handbook and pre-printed perioperative order forms for surgical antibiotic prophylaxis: Do they work? Can J Surg 1990;33:385-8.

3. Kunin CM. Evaluation of antibiotic usage: A comprehensive look at alternative approaches. Rev Infect Dis 1981;3:745-53.

4. Pestotnik SL, Classen DC, Evans RS, Burke JP. Implementing antibiotic practice guidelines through computer-assigned 
decision support: Clinical and financial outcomes. Ann Intern Med 1996;124:884-90.

5. Maki DG, Schuna AA. A study of antimicrobial misuse in a university hospital. Am J Med Sci 1978;275:271-82.

6. Schaffner W, Ray WA, Federspiel CF. Surveillance of antibiotic prescribing in office practice. JAMA 1983;250:1728-32.

7. Abramowitz PW, Nold EG, Hatfield SM. Use of clinical pharmacists to reduce cefamandole, cefoxitin, and ticarcillin costs. Am J Hosp Pharm 1982;39:1176-80.

8. Britton HL, Schwinghammer TT, Romano MJ. Cost containment through restriction of cephalosporins. Am J Hosp Pharm 1981;38:1897-900.

9. Hayman JN, Sbravati EC. Controlling cephalosporin and aminoglycoside costs through pharmacy and therapeutics committee restrictions. Am J Hosp Pharm 1985;42:1343-7.

10. McCloskey WW, Johnson PN, Jeffery LP. Cephalosporin-use restriction in teaching hospitals. Am J Hosp Pharm 1984;41:2359-62.

11. Shibal AM, Sande MA. New cephalosporin antibiotics: selection and uses. Hosp Formul 1985;20:802-8.

12. Baum C, Kennedy DL, Forbes MB, Jones JK. Drug use and expenditures in 1982. JAMA 1985;253:382-6.

13. Zelenitsky S, Chony R, Danzinger R. An evaluation of perioperative antimicrobial use and surgical site infection rates in general surgery. Can J Hosp Pharm 1996;49:13-9.

14. Frighetto L, Nickoloff D, Jewesson P. Antibiotic therapeutic interchange program: Six years of experience. Hosp Formul 1995;30:92-105

15. Salama SE, Rotstein C, Mandell L. A multidisciplinary hospital-based antimicrobial use program: Impact on hospital pharmacy expenditures and drug use. Can J Infect Dis 1996; $7: 104-9$

16. Haley RW, Culver DH, White JW, Morgan WM, Emori TG. The nationwide nosocomial infection rate: A new need for vital statistics. Am J Epidemiol 1985;121:159-67.

17. Altemeier WA, Burke JF, Pruitt BA, et al, eds. Manual on Control of Infection in Surgical Patients, 2nd edn. Philadelphia: JB Lippincott, 1984.

18. Polk HC Jr, Lopez-Mayor JF. Postoperative wound infection: A prospective study of determinant factors and prevention. Surgery 1969;66:97-103.

19. Stone HH, Hooper CA, Kolb LD, et al. Antibiotic prophylaxis in gastric, biliary and colonic surgery. Ann Surg 1976;184:443-52.

20. Platt R, Zaleznik DF, Hopkins CC, et al. Perioperative antibiotic prophylaxis for herniorrhaphy and breast surgery. N Engl J Med 1990;322:153-60.

21. Lewis RT, Weigand FM, Mamazza J, Lloyd-Smith W, Tataryn D. Should antibiotic prophylaxis be used routinely in clean surgical procedures: A tentative yes. Surgery 1995;118:742-7.

22. Watkin DS, Wainwright AM, Thompson MH, et al. Infection after laparoscopic cholecystectomy: Are antibiotics really necessary? Eur J Surg 1995;161:509-11.

23. Wilson AP. Antibiotic prophylaxis and infection control measures in minimally invasive surgery. J Antimicrob Chemother 1995;36:1-5.

24. Shapiro M. Use of antimicrobial agents in general hospitals. N Engl J Med 1979;301:351-5.

25. Larsen RA, Evans RS, Burke JP, Pestotnik SL, Gardner RM, Classen DC. Improved perioperative antibiotic use and reduced surgical wound infections through use of computer decision analysis. Infect Control Hosp Epidemiol 1989;10:316-20.

26. Nichols RL. Surgical antibiotic prophylaxis. Med Clin North Am 1995;79:509-21.

27. Kaiser AB. Antimicrobial prophylaxis in surgery. N Engl J Med 1986;315:1129-38.

28. Martin C, the French Study Group on Antimicrobial Prophylaxis in Surgery, the French Society of Anesthesia and Intensive Care. Antimicrobial prophylaxis in surgery: General concepts and clinical guidelines. Infect Control Hosp Epidemiol 1994;15:463-71.

29. Dellinger EP, Gross PA, Barrett TL, et al. Quality standard for antimicrobial prophylaxis in surgical procedures. Infect Control Hosp Epidemiol 1994;15:182-8.
30. Dickinson GM, Bisno AL. Antimicrobial prophylaxis of infection. Infect Dis Clin North Am 1995;9:783-90.

31. ASHP Commission on Therapeutics. Special feature: ASHP therapeutic guidelines on antimicrobial prophylaxis in surgery. Clin Pharm 1992;11:483-513.

32. Committee on Antimicrobial Agents, Canadian Infectious Disease Society, Waddell TK, Rotstein OD. Antimicrobial prophylaxis in surgery. Can Med Assoc J 1994;151:925-31.

33. Anon. Antimicrobial prophylaxis in surgery. Med Letter 1993;35:91-4

34. Dajani AS, Bisno AL, Chung KJ, et al. Prevention of bacterial endocarditis - Recommendations by the American Heart Association. JAMA 1990;264:2919-22.

35. Page CP, Bohnen JMA, Fletcher JR, et al. Antimicrobial prophylaxis for surgical wounds: Guidelines for clinical care. Arch Surg 1993;128:79-99.

36. Evans CE, Haynes RB, Birkett NJ, et al. Does a mailed continuing education program improve physician performance? Results of a randomized trial in antihypertensive care. JAMA 1986;255:501-4.

37. Jones SR, Bark J, Bratten T, et al. The effect of an educational program upon hospital antibiotic use. Am J Med Sci 1977;273:79-85.

38. Herfindal ET, Bernstein LR, Kishi DT. Effect of clinical pharmacy services on prescribing on an orthopedic unit. Am J Hosp Pharm 1983;40:1945-51.

39. DeSilva MI, Mize GN, Rissing JP. Peer review of antibiotic use: positive impact on physician prescribing patterns. $Q$ Rev Biol 1985;10:302-5.

40. Avorn J, Soumerai SB. Improving drug therapy decisions through educational outreach. A randomized controlled trial of academically based ‘detailing'. N Engl J Med 1983;308:1457-63.

41. D'eramo JE, Dupont HL, Preston GA, et al. The short and long term effects of a handbook on antimicrobial prescribing patterns of hospital physicians. Infect Control 1983;4:209-14.

42. Pitre M, Conly JM. Use of an antimicrobial handbook as a tool for continuous quality improvement in the antimicrobial prescribing process. Ontario Medical Association - the Drug Report 1995;51:1-2.

43. Marr JJ, Moffet HL, Kunin CM. Guidelines for improving the use of antimicrobial agents in hospitals. A statement by the Infectious Disease Society of America. J Infect Dis 1988;157:869-76.

44. Plumridge RJ. A review of factors influencing drug prescribing I. Aust J Hosp Pharm 1983;13:16-9.

45. Echols RM, Kowalsky SF. The use of antibiotic order form for antibiotic utilization review: Influence on physicians' prescribing patterns. J Infect Dis 1984;150:803-7.

46. Durbin WA, Lapidas B, Goldmann DA. Improved antibiotic usage following introduction of a novel prescription system. JAMA 1981;246:1796-800.

47. Soumerai SB, Avorn J, Taylor WC, Wessels M, Maher D, Hawley SL. Improving choices of prescribed antibiotics through concurrent reminders in an educational order form. Med Care 1993;31:552-8.

48. Avorn J, Soumerai SB, Taylor W, Wessels MR, Janousek J, Weiner $M$. Reduction of incorrect antibiotic dosing through a structured educational order form. Arch Intern Med 1988;148:1720-4.

49. Centers for Disease Control and Prevention. Nosocomial enterococci resistant to vancomycin - United States, 1989-1993. Morb Mortal Wkly Rep 1993;42:597-9.

50. Hospital Infection Control Practices Advisory Committee. Recommendations for preventing the spread of vancomycin resistance. Infect Control Hosp Epidemiol 1995;16:105-13.

51. Mithani H, Brown G. The economic impact of once-daily versus conventional administration of gentamicin and tobramycin. Pharmacoeconomics 1996;10:494-503.

52. Wong-Beringer A, Corelli RL, Schrock TR, Guglielmo J. Influence of timing of antibiotic administration on tissue concentrations during surgery. Am J Surg 1995;169:379-81.

53. Classen DC, Evans RS, Pestotnik SL, Horn SD, Menlove RL, Burke JP. The timing of prophylactic administration of antibiotics and the risk of surgical wound infection. $\mathrm{N}$ Engl J Med 1992;326:281-6. 


\section{Hamilton Civic Hospitals}

\section{Henderson General Division}

\section{Perioperative Antibiotic Prophylaxis Order Form}

- Please check the appropriate box and sign the order form. (If coverage for endocarditis prophylaxis is necessary, please fill in the accompanying form as well.)

1) Biliary Tract

(For: $>60$ yr. old, previous biliary surgery, acute symptoms of cholecystitis, common duct stones or presence of jaundice)

$\square$ cefazolin $1 \mathrm{~g} I V$ just prior to transfer to OR

D clindamycin $600 \mathrm{mg} I V+$ gentamicin $80 \mathrm{mg}$ IV just prior to transfer to $O R$

2) Gastroduodenal Surgery

(For: Bleeding gastric or duodenal ulcer, obstructive duodenal ulcer or gastric ulcer, gastric malignancy, chronic $\mathrm{H}_{2}$ antagonist therapy, morbid obesity or percutaneous endoscopic gastrostomy (PEG))

$\square$ cefazolin $1 \mathrm{~g}$ IV just prior to transfer to $O R$

$$
\text { - or - }
$$

If beta-lactam allergy:

$\square$ clindamycin $600 \mathrm{mg}$ IV + gentamicin $80 \mathrm{mg}$ IV just prior to transfer to $O R$

3) Appendectomy Without Peritonitis Or Perforation

$\square$ clindamycin $600 \mathrm{mg}$ IV + gentamicin $80 \mathrm{mg}$ IV just prior to transfer to $O R$

$$
\text { - or - }
$$

(If no beta-lactam allergy:)

$\square$ cefotetan 1 g IV just prior to transfer to OR

\section{4) Elective Colon and Small Bowel Surgery}

$\square$ clindamycin $600 \mathrm{mg}$ IV + gentamicin $80 \mathrm{mg}$ IV just prior to transfer to $O R$

$$
\text { - or - }
$$

(If no beta-lactam allergy:)

$\square$ cefotetan $1 \mathrm{~g} \mathrm{IV}$ just prior to transfer to $O R$

\section{5) Herniorrhaphy}

cefazolin $1 \mathrm{~g}$ IV just prior to transfer to $O R$

$$
\text { - or - }
$$

If beta-lactam allergy:

clindamycin $600 \mathrm{mg}$ IV + gentamicin $80 \mathrm{mg}$ TV just prior to transfer to $O R$

6) Division of Adhesions or Laparotomy Not Involving a Hollow Viscus

clindamycin $600 \mathrm{mg} I V+$ gentamicin $80 \mathrm{mg}$ IV just prior to transfer to $O R$ - or -

(If no beta-lactam allergy:)

$\square$ cefotetan $1 \mathrm{~g}$ IV just prior to transfer to $O R$

7) Mastectomy +1-Lymph Node Dissection

$\square$ cefazolin $1 \mathrm{~g}$ IV just pricr to transfer to $O R$

$\square$ clindamycin $600 \mathrm{mg}$ IV just prior to transfer to $O R$

NO PROPHYLAXIS - Please specify the type of surgery:

Doctor's signature: (Date: I 


\section{Hamilton Civic Hospitals \\ Henderson General Division \\ Perioperative Antibiotic Prophylaxis Order Form}

- Please check the appropriate box and sign the order form.

\section{1) Arthroplasty of Joints Including Replacement \\ $\square$ cefazolin $1 \mathrm{~g}$ IV just prior to transfer to OR \& then repeat $\mathrm{q} 8 \mathrm{~h} \times 2$ doses \\ -or -}

If beta-lactam allergy or if Methicillin-resistent staphylococci frequently cause wound infections:

vancomycin $1 \mathrm{~g} \mathrm{IV}+$ gentamicin $80 \mathrm{mg}$ IV just prior to transfer to $O R$ \& then repeat $\mathrm{q} 12 \mathrm{~h} \times 1$ dose

2) Open Reduction and Internal Fixation of Fracture and/or Insertion of Any Orthopedic Device

$\square$ cefazolin $1 \mathrm{~g} \mathrm{IV}$ just prior to transfer to OR \& then repeat $\mathrm{q} 8 \mathrm{~h} \times 2$ doses

- or -

If beta-lactam allergy or if Methicillin-resistent staphylococci frequently cause wound infections:

Q vancomycin $1 \mathrm{~g} \mathrm{IV}+$ gentamicin $80 \mathrm{mg}$ IV just prior to transfer to $O R$ \& then repeat $\mathrm{q} 12 \mathrm{~h} \times 1$ dose

\section{3) Osteotomy}

$\square$ cefazolin $1 \mathrm{~g}$ IV just prior to transfer to OR \& then repeat $\mathrm{q} 8 \mathrm{~h} \times 2$ doses

- or -

If beta-lactam allergy or if Methicillin-resistent staphylococci frequently cause wound infections:

$\square$ vancomycin $1 \mathrm{~g} \mathrm{IV}+$ gentamicin $80 \mathrm{mg} \mathrm{IV}$ just prior to transfer to $O R \&$ then repeat $\mathrm{q} 12 \mathrm{~h} \times 1$ dose

\section{4) Anterior Cruciate Ligament Repair}

$\square$ cefazolin $1 \mathrm{~g}$ IV just prior to transfer to OR \& then repeat $\mathrm{q} 8 \mathrm{~h} \times 2$ doses

- or -

If beta-lactam allergy or if Methicillin-resistent staphylococci frequently cause wound infections:

D vancomycin $1 \mathrm{~g}$ IV + gentamicin $80 \mathrm{mg}$ IV just prior to transfer to OR \& then repeat $\mathrm{q} 12 \mathrm{~h} \times \mathrm{I}$ dose

\section{5) Excision of Tumour}

$\square$ cefazolin $1 \mathrm{~g}$ IV just prior to transfer to OR \& then repeat $\mathrm{q} 8 \mathrm{~h} \times 2$ doses

- or -

If beta-lactam allergy or if Methicillin-resistent staphylococci frequently cause wound infections:

$\square$ vancomycin $1 \mathrm{~g} \mathrm{IV}+$ gentamicin $80 \mathrm{mg} \mathrm{IV} \mathrm{just} \mathrm{prior} \mathrm{to} \mathrm{transfer} \mathrm{to} \mathrm{OR} \mathrm{\&} \mathrm{then} \mathrm{repeat} \mathrm{q12h} \times 1$ dose

\section{6) Laminectomy \& Spinal Fusion}

$\square$ No prophylaxis

7) Lower Limb Amputation (Diabetic Patient)

$\square$ clindamycin $600 \mathrm{mg} \mathrm{IV}$ + gentamicin $80 \mathrm{mg}$ IV just prior to transfer to $O R$

- or -

(If no beta-lactam allergy:)

$\square$ cefotetan $1 \mathrm{~g}$ IV just prior to transfer to $\mathrm{OR}$ 


\section{Hamilton Civic Hospitals}

Henderson General Division

\section{Perioperative Antibiotic Prophylaxis Order Form}

- Please check the appropriate box and sign the order form.

\section{1) Endoscopic Surgery}

$\square$ cefazolin $1 \mathrm{~g}$ IV just prior to transfer to OR \& then repeat $\mathrm{q} 8 \mathrm{~h} \times 1$ dose

- or -

ampicillin $\mathbf{2} \mathrm{g} \mathrm{IV}+$ gentamicin $\mathbf{8 0} \mathrm{mg} \mathrm{IV}$ just prior to transfer to OR \& then repeat ampicillin $\mathbf{2} \mathrm{g}$ IV q6h $\times 1$ dose + gentamicin $80 \mathrm{mg}$ IV q $8 \mathrm{~h} \times 1$ dose

- or -

If beta-lactam allergy:

$\square$ vancomycin $1 \mathrm{~g} \mathrm{IV} \mathrm{+} \mathrm{gentamicin} 80 \mathrm{mg} \mathrm{IV} \mathrm{just} \mathrm{prior} \mathrm{to} \mathrm{transfer} \mathrm{to} \mathrm{OR} \mathrm{\&} \mathrm{then} \mathrm{repeat} \mathrm{gentamicin} 80 \mathrm{mg} \mathrm{IV} \mathrm{q8h} \times 1$ dose

\section{2) Prosthetic Imnlants + Open Surgery Not Involving Bowel}

$\square$ cefazolin $1 \mathrm{~g}$ IV and gentamicin $80 \mathrm{mg}$ IV just prior to transfer to OR \& then repeat $\mathrm{q} 8 \mathrm{~h} \times 1$ dose

$$
\text { - or - }
$$

$\square$ vancomycin $1 \mathrm{~g} \mathrm{IV}+$ gentamicin $80 \mathrm{mg}$ IV just prior to transfer to OR \& then repeat gentamicin $80 \mathrm{mg} I V$ q $8 \mathrm{~h} \times 1$ dose

$$
\begin{aligned}
& \text { 3) Open Surgery Involving Bowel } \\
& \square \text { clindamycin } 600 \mathrm{mg} \mathrm{IV}+\text { gentamicin } 80 \mathrm{mg} \text { IV just prior to transfer to OR } \\
& \text { - or - } \\
& \text { (If no beta-lactam allergy:) } \\
& \square \text { cefotetan } 1 \mathrm{~g} \mathrm{IV} \mathrm{just} \mathrm{prior} \mathrm{to} \mathrm{transfer} \mathrm{to} \mathrm{OR}
\end{aligned}
$$

\section{4) Prevention of Bacterial Endocarditis}

$\square$ ampicillin $2 \mathrm{~g} \mathrm{IV} \mathrm{+} \mathrm{gentamicin} 80 \mathrm{mg}$ IV just prior to transfer to OR \& then repeat both drugs 8 hours after initial dose -or If beta-lactam allergy:

$\square$ vancomycin $1 \mathrm{~g} I \mathrm{~V}+$ gentamicin $80 \mathrm{mg}$ IV just prior to transfer to OR \& then repeat gentamicin $80 \mathrm{mg}$ IV q8h $\mathrm{x} 1 \mathrm{dose}$

NO PROPHYLAXIS - Please specify the type of surgery:

\section{Doctor's signature:}

(Date:

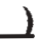




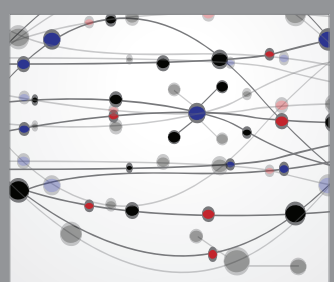

The Scientific World Journal
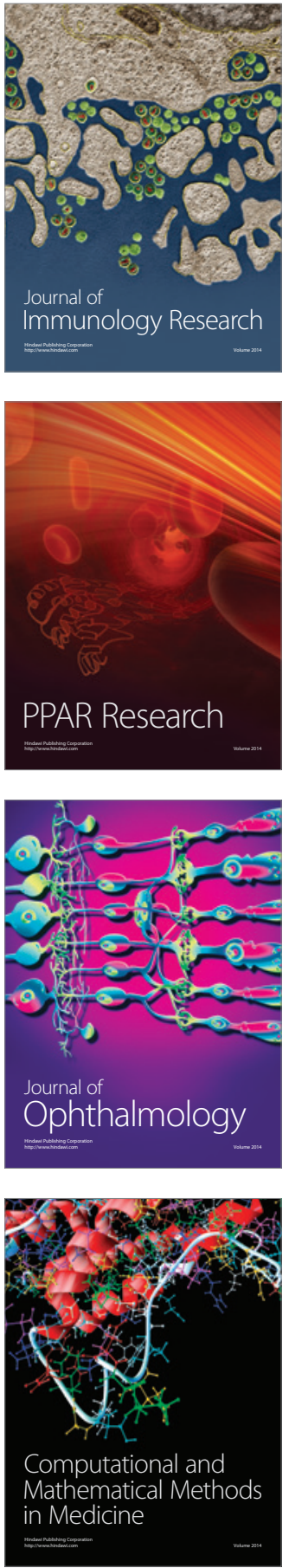

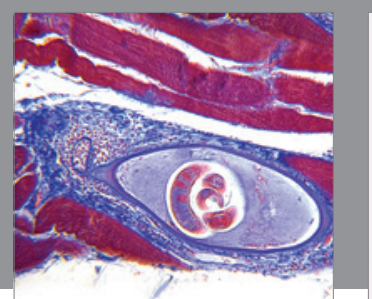

Gastroenterology Research and Practice

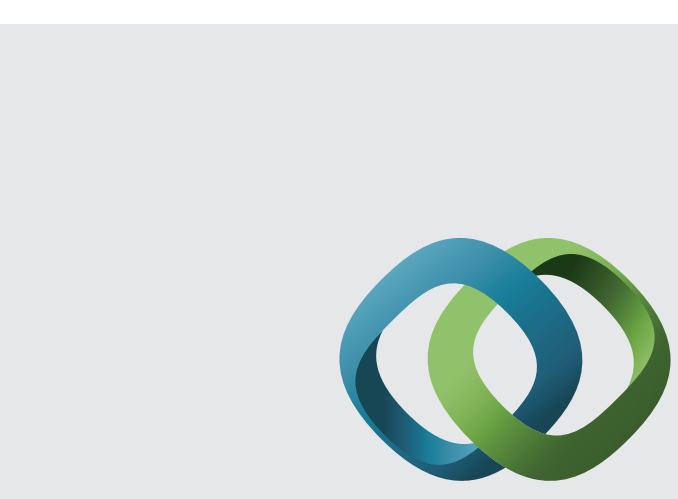

\section{Hindawi}

Submit your manuscripts at

http://www.hindawi.com
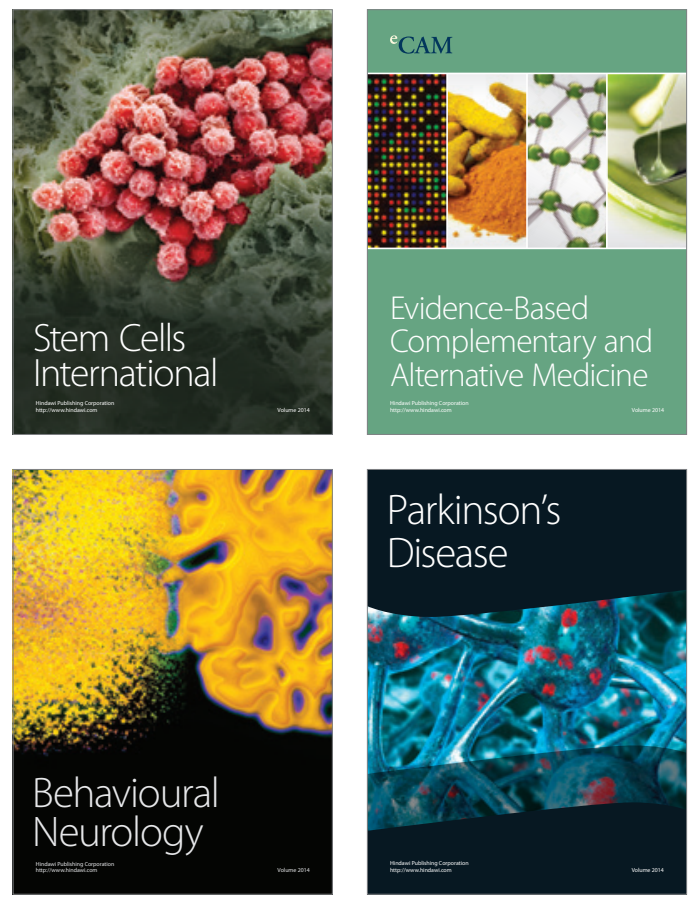
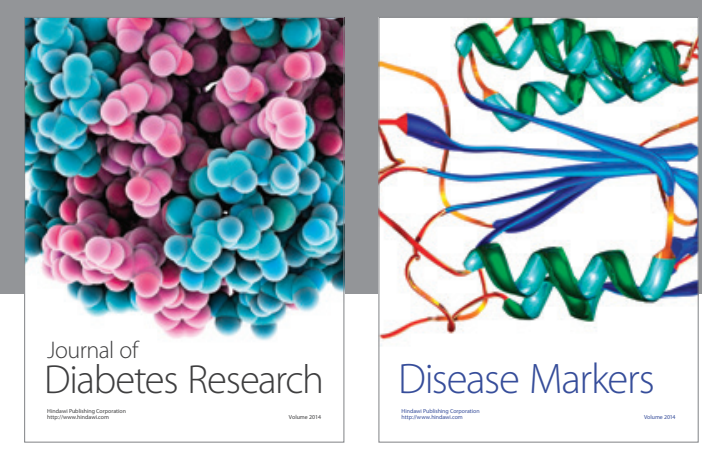

Disease Markers
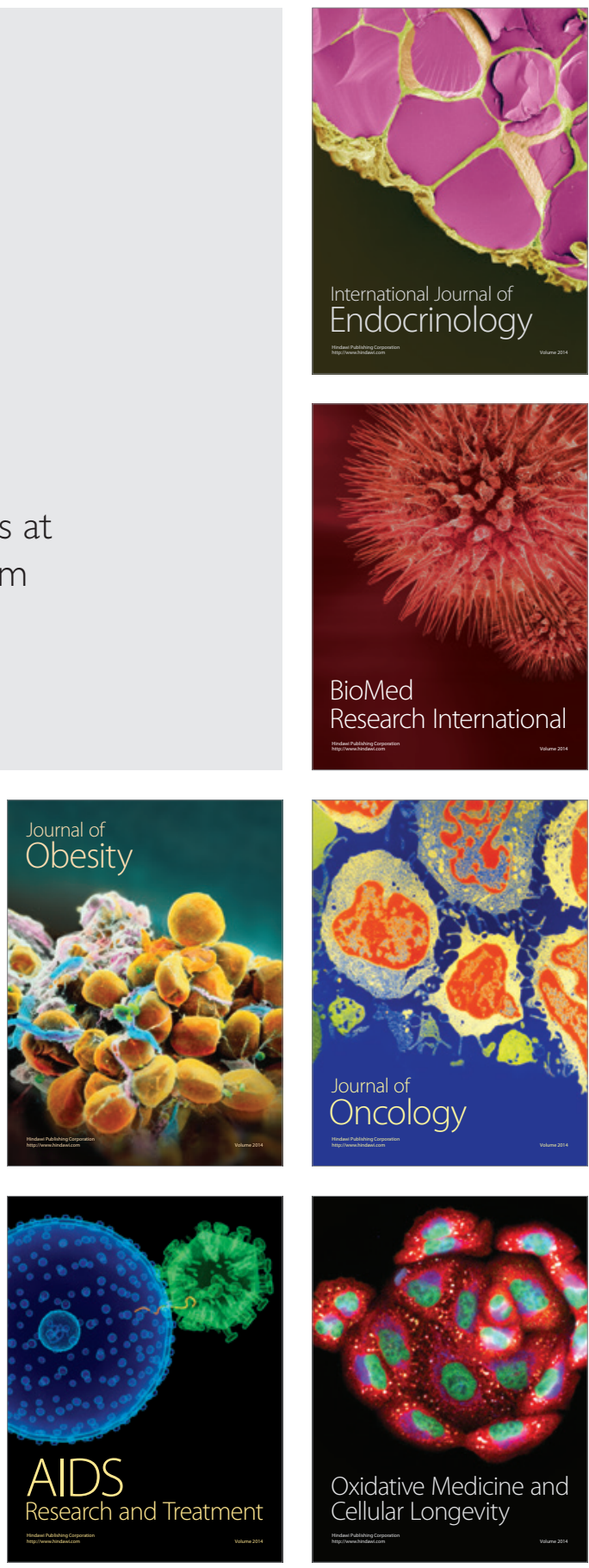